\title{
ARTIGO
}

\section{Microlesões no Direito do Trabalho}

\author{
Microinjuries in the Labour Law \\ Microlesiones en el Derecho del Trabajo
}

\section{Otávio Rodrigues Kolowski ${ }^{1}$ Marina Cunha Sampaio²}

RESUMO: O presente artigo procura analisar o conceito de microlesão à luz do Direito do Trabalho, com o objetivo de discutir a prática empresarial de microlesionar empregados como forma de garantir competitividade econômica frente à concorrência, bem como suas consequências para a classe trabalhadora e à sociedade. Ademais, é debatida a política institucional dos órgãos de regulação do trabalho frente à questão.

Palavras-chave: Direito do Trabalho; microlesão; dumping social; terceirização; assédio moral.

ABSTRACT: This article aims to analyze the concept of micro-injury in the light of Labour Law. The objective is to discuss the business practice of micro-injuring employees as a way of guaranteeing economic competitiveness against the rivalry, as

\footnotetext{
${ }^{1}$ Auditor-Fiscal do Trabalho, Ministério do Trabalho, Rio Grande do Sul.

2 Auditora-Fiscal do Trabalho, Ministério do Trabalho, São Paulo; Especialista em Direito e Processo do Trabalho (Anhanguera-Uniderp). E-mail: marina_sampaio@hotmail.com

Laborare. Ano I, Número 1, Julho/2018, pp. 31-61-. ISSN 0000-0000. http://trabalhodigno.org/laborare
} 
well as its consequences for the working class and society. Finally, Brazilian Federal Labour Inspection System's as well as Public Ministry of Labour's and Labour Justice's institutional policy against micro damaging is discussed.

Keywords: Labour Law; micro-injury; social damage; outsourcing; harassment.

\section{INTRODUÇÃO}

Originariamente, o conceito de microlesão, enquanto pequeno dano ocasionado por ação objetiva em prejuízo de outrem, foi mobilizado pelo ramo do Direito do Consumidor e ilustra a situação em que o comprador de determinado produto ou serviço sofre dano, cujo valor, individualmente considerado, é inexpressivo. No entanto, quando esses microtraumas são replicados a uma coletividade de consumidores tornam-se economicamente significativos para as empresas infratoras.

A necessidade da garantia de lucro imposta pelo sistema político-econômico capitalista resulta na criação e utilização das mais diversas estratégias para a competitividade e consequente sobrevivência empresarial. Destarte, não raras as vezes, a burla à lei é empregada para alcançar tais objetivos, de modo que o inadimplemento voluntário a direitos de credores com o propósito de obtenção de lucro consiste em prática corriqueira no meio corporativo.

No Direito do Trabalho, o perfil típico dos respectivos credor e devedor, isto é, trabalhador e empregador, se confunde com os perfis equivalentes no Direito Consumeirista. O empresário que pratica microlesões ao consumidor é também um empregador. Já os empregados apresentam o mesmo ou até um maior grau de hipossuficiência do que os consumidores lesados pelo empresário. Dessa forma, 
sendo a microlesão uma prática dolosa de obtenção de lucro e de prejuízo à concorrência por violações sistemáticas e repetitivas à lei consumeirista, é também esperada (considerada a lógica econômica vigente) que a prática seja replicada em relação a direitos trabalhistas.

Assim, similarmente ao que ocorre nas relações entre capital e consumo, nas relações entre capital e trabalho, a assimetria de forças entre empregadores e empregados possibilita aos primeiros o desenvolvimento das mais variadas técnicas de gestão e organização do trabalho para a maximização dos lucros. A transferência dos riscos do empreendimento a terceiros, a submissão de trabalhadores a condições análogas a de escravos e a recente uberização do trabalho são exemplos dessas estratégias empresariais. Amplamente praticada no país, a microlesão trabalhista ${ }^{3}$ se inclui nesse rol.

O objetivo deste artigo é discutir a transposição do conceito de microlesão criado pelo Direito do Consumidor para o Direito do Trabalho brasileiro, como forma de gestão empresarial da força de trabalho, que permite o ganho de competitividade frente a outras empresas em detrimento da saúde, da segurança e da dignidade do trabalhador. Para tanto, se faz necessário compreender sua caracterização e as condições necessárias para sua efetivação enquanto estratégia para obtenção de lucro por meio da fraude a direitos sociais. Procuramos, em particular, analisar a atuação do Estado frente a esses ilícitos.

A argumentação divide-se em seis seções: a primeira inaugura a conceituação de microlesão no Direito Trabalhista e explica como a fraude a direitos sociais é

\footnotetext{
${ }^{3}$ É importante esclarecer que a utilização dos termos "microlesão", "pequenas agressões", "pequenos danos" e outros utilizados nesse artigo não denotam a minimização do problema e não significa dizer que as referidas lesões são inexpressivas ou desimportantes. Pelo contrário, consideramos que cada infração corresponde a uma violação, a uma condição mínima e indisponível de ter o Direito do Trabalho inteiramente cumprido. É por esse motivo que defendemos, nesse artigo, a aplicação integral da legislação trabalhista pelos agentes públicos dos órgãos de regulação do trabalho.
}

Laborare. Ano I, Número 1, Julho/2018, pp. 31-61. ISSN 0000-0000. http://trabalhodigno.org/laborare 
utilizada como ferramenta de organização do trabalho; a segunda indica quais as condições necessárias para a implementação da referida estratégia empresarial; a terceira demonstra que a rotatividade de empregados e o assédio moral são praticados em diversas ocasiões de forma deliberada com o intuito de mascarar as microlesões trabalhistas, eis que dificultam a detecção pelos órgãos responsáveis pela tutela do trabalhador, diminuem as probabilidades de reclamações por parte dos trabalhadores e, consequentemente, reduzem as chances de penalização das empresas infratoras; o quarto tópico discute a relação entre microlesão e dumping social, e o quinto demonstra que as diretrizes predominantes do Ministério do Trabalho, do Ministério Público do Trabalho e da Justiça do Trabalho reforçam e estimulam a prática das microlesões trabalhistas. A última seção retoma a tese de que as microlesões trabalhistas são instrumentos estratégicos de gestão do trabalho e defende, a título de conclusão, a necessidade de revisão e reformulação das políticas institucionais de combate às fraudes aos direitos sociais trabalhistas.

\section{MICROLESÕES TRABALHISTAS: A FRAUDE A SERVIÇO DO LUCRO}

O estratagema de microlesionar consiste em obter lucro mediante a prática pulverizada de um determinado prejuízo a uma coletividade de credores. Ao invés de lesar um único credor, em valor de alta expressão e por meio de sonegação integral de direito deste, operam-se pequenas lesões a uma grande quantidade de credores.

No Direito do Consumidor, exemplos desse artifício são a efetivação de pequenos descontos de serviços não solicitados em faturas de telefonia, de "taxas" desprovidas de previsão contratual em contas bancárias ou venda de produtos com pequenas diferenças a menor de qualidade ou quantidade entre aquilo que fora anunciado e aquilo que fora efetivamente fornecido. Individualmente, são lesões irrelevantes, contudo, quando aplicadas em um número suficientemente grande de vítimas e/ou 
repetidas um número suficientemente grande de vezes, podem alcançar com facilidade quantias multimilionárias.

O acórdão n ${ }^{\circ} 70056397896$ (Rio Grande do Sul, 2013) exemplifica a prática da microlesão, no caso referente à cobrança de serviços não solicitados de assinaturas de revistas:

De fato, pela nossa experiência, como julgadores, sabemos que se contam aos milhares as demandas semelhantes a esta, de consumidores indignados com a cobrança por supostos serviços que não foram solicitados, mas que são cobrados em faturas de cartão de crédito, benefícios previdenciários e contas de telefonia, seja fixa ou celular.

O número assombroso de demandas assemelhadas está a apontar claramente que não se trata de meras disfunções e descontroles pontuais - que seriam resolvidos mediante a simples restituição dos valores, sem se falar em danos morais. Trata-se de verdadeira política de relacionamento adotada conscientemente pelas empresas requeridas.

No campo da responsabilidade civil, tal prática abusiva vem causando danos que configuram 'microlesões' do ponto de vista individual, mas que globalmente são relevantes. Ou seja, são estratégias que, individualmente consideradas, beiram à irrelevância para o operador econômico, causando pequena lesão ao consumidor. Todavia, consideradas em seu conjunto, acarretam grandes lucros aos fornecedores. E é isso que deve ser levado em conta quando o julgador é levado a decidir sobre uma dessas microlesões, como é o caso.

Uma tal política, que ofende a cidadania, não pode receber o aval do Judiciário, que indiretamente estaria estimulando tal prática nefasta se simplesmente determina a restituição simples dos valores recebidos indevidamente, pois, convenha-se, devolver somente o que se recebeu indevidamente significa simplesmente devolver o que nunca lhe pertenceu por direito, sem qualquer penalização.

Conforme se observa, a microlesão caracteriza-se pela reiteração de ações danosas que possuem aparente irrelevância do ponto de vista individual, mas que são expressivamente vantajosas do ponto de vista econômico quando consideradas em sua

Laborare. Ano I, Número 1, Julho/2018, pp. 31-61. ISSN 0000-0000. http://trabalhodigno.org/laborare 
totalidade. O prejuízo é dolosamente cometido pela empresa contra consumidores com o objetivo de ganho de vantagem econômica.

No Direito do Trabalho, microlesões são fraudes pequenas e aplicadas de forma discreta que, muitas vezes, são tidas como "erros" de contagem ou de cálculo do pagamento de determinadas verbas trabalhistas ou mesmo de enquadramento jurídico de determinadas situações, que se repetem ao longo de sucessivas parcelas inadimplidas ou parcialmente adimplidas durante o curso do contrato de trabalho.

Algumas dessas técnicas em matéria de legislação trabalhista são: pagamento a menor de horas extras e de gorjetas, redução de intervalos para descanso com ou sem o correspondente pagamento salarial, ausência ou pagamento parcial de horas in itinere, desconsideração de determinadas parcelas como base para o cálculo do FGTS, erro no enquadramento legal em prejuízo do trabalhador, ausência de pagamento de verbas acordadas em instrumento normativo da categoria, entre outras.

No âmbito da medicina e da segurança do trabalho, consideram-se microlesões as agressões diárias discretas a que são submetidos os empregados e que poderiam passar despercebidas por uma análise acrítica ou atécnica do meio ambiente do trabalho e da forma de organização do trabalho, porém, com grande potencial deletério à saúde e à segurança dos trabalhadores. Condições ambientais não ergonômicas, exposição a ruídos, iluminação ou agentes químicos e biológicos, cobrança excessiva de metas, limitação de ir ao banheiro, de tomar água, são algumas dessas formas de lesão.

Exemplo da prática de microlesão é trazido pelo histórico de uma das empresas líderes de mercado de processamento de carnes, cujo lucro foi de $\mathrm{R} \$ 323$ milhões no terceiro trimestre de 2017. Segundo dados do Sistema Federal de Inspeção do 
Trabalho, entre janeiro de 2013 e março de 2018, suas unidades sofreram 1.843 autuações aplicadas por 116 diferentes Auditores Fiscais do Trabalho, relativas a 554 infrações também diversas.

Múltiplas atuações dizem respeito a infrações que chegaram a serem flagradas em mais de 20 ocasiões diversas, isto é, o empregador continuava a repetir a exata infração mesmo após ter sido autuado mais de duas dezenas de vezes, nos últimos cinco anos. Não há, portanto, qualquer possibilidade de a infração ser praticada por motivo de desconhecimento da legislação e falta de orientação prévia. Apesar da óbvia recalcitrância, não há um cenário de violações ostensivas praticado de forma generalizada. Ausentes quaisquer flagrantes estatisticamente relevantes de infrações grosseiras como mão de obra informal, sonegação de parcelas ordinárias de FGTS ou sonegação total de parcelas salariais ou de verbas rescisórias, que seriam razões para fácil vitória de qualquer trabalhador que viesse a demandar a empresa na Justiça do Trabalho.

As irregularidades recorrentes dizem respeito a violações mais discretas com efeitos indiretos e menores na remuneração do trabalhador, como excesso de jornada e falta de descanso, cuja multa não é calculada per capita. Ou, ainda, a infrações cuja detecção e reclamação não são feitas por trabalhador ordinário, mas sim por autoridade fiscal, tais como falta de contratação de aprendizes e violações a normas de segurança laboral, especialmente relacionadas a máquinas, ergonomia e medicina do trabalho. Ou seja, há uma seletividade bastante clara em relação a quais normas o empregador cumpre ou não, baseada em critérios aparentes da dificuldade em sua detecção e penalização. Um cenário bastante compatível com o modelo teórico da prática de microlesões.

As condutas da empresa, muito longe de representarem desconhecimento acerca da legislação, denotam comportamento infrator sistemático, cujo intuito é obter vantagem econômica em detrimento da remuneração e do meio ambiente do 
trabalho devidos ao trabalhador. Referidos comportamentos são resultados de decisão empresarial sobre a forma de gestão do trabalho que melhor convém à extração de mais-valia.

É necessário enfatizar que nas sociedades em que o modo de produzir é o capitalista, o trabalho é condição sine qua non para a existência do valor, em especial, do mais valor (fundamento do lucro capitalista), eis que é a ferramenta indispensável e pela qual se extrai a mais-valia. Nesse sistema, o trabalho se equipara à mercadoria, na medida em que é vendido ao capitalista em forma de força de trabalho, em troca de salário - salário esse que será utilizado pelo operário para comprar mercadorias de que necessita para sobreviver. Equipara-se, pois, a força de trabalho a qualquer outra mercadoria e consome-se o trabalho como se consome qualquer outra, de forma produtiva (Marx, 2006, 2013).

E, igualmente ao que ocorre com as mercadorias em geral, o próprio trabalho é estranho ao trabalhador na medida em que, sendo a força de trabalho imprescindível ao capitalista por produzir para ele mais valor do que ela mesma possui, seu controle e propriedade são alienados do trabalhador (Marx, 2006, 2013). As condições em que o trabalho será executado, desde seu valor e quantidade de horas até questões afetas à sua saúde e segurança no trabalho são determinadas unilateralmente pelo empregador.

Nesse sentido, a forma escolhida pela empresa para a gestão do trabalho levará em conta as condições de utilização da força de trabalho que lhe forem mais favoráveis, ou seja, que, em última análise, lhe permitirem a maior acumulação de capital. Um exemplo pode ser observado com relação a empresas do grupo econômico de uma das maiores construtoras da América do Sul e do mundo, cuja receita bruta, em 2015, foi de 132 bilhões de reais: entre 2013 e 2017, essas empresas foram fiscalizadas pelo Sistema Federal de Inspeção do Trabalho e flagradas descumprindo a legislação Laborare. Ano I, Número 1, Julho/2018, pp. 31-61. ISSN 0000-0000. http://trabalhodigno.org/laborare 
trabalhista em 404 (quatrocentos e quatro) situações, dentre as quais pelo menos 217 (duzentos e dezessete) infrações concorreram direta ou indiretamente para a submissão dos trabalhadores a riscos de acidentes de trabalho ${ }^{4}$. Quando interditada, em 11/03/2014, ante o flagrante de exposição dos trabalhadores a riscos graves e iminentes à sua saúde e segurança, em vez de paralisar as atividades e corrigir as irregularidades, a empresa optou por dar prosseguimento aos trabalhos e arriscar a vida dos empregados, infringindo novamente a legislação, o que ensejou a lavratura do Auto de Infração no 20.312.287-9, datado de 21/03/2014 ${ }^{5}$, que teve como objeto a exposição dolosa de trabalhadores a riscos graves e iminentes formalmente registrados em ordem expressa de interdição ignorada pela empresa e que justamente ordenava a paralisação das atividades e saneamento dos riscos.

\section{CONDIÇÕES PARA A PRÁTICA DE MICROLESÕES TRABALHISTAS}

Em regra, a decisão organizacional de infringir ou não a legislação é tomada por meio de critérios financeiros e probabilísticos que variam sobre o quanto inadimplir, a quem lesar, a probabilidade de o prejudicado vir a detectar a lesão e adotar medidas destinadas a ressarcimento e, por fim, sobre a efetiva perspectiva de tais ações reparatórias e punitivas virem a ter eficácia. A prática de determinada fraude depende, portanto, da satisfação de condições específicas que levem a um resultado positivo quando do cálculo do custo-benefício para sua implementação.

O quadro abaixo ilustra de forma esquemática e simples as condições necessárias para a prática das microlesões trabalhistas:

\footnotetext{
${ }^{4}$ A despeito de concorrerem para a ocorrência de acidentes e adoecimentos do trabalho, foram excluídas, por motivos metodológicos, as irregularidades constatadas por infrações relativas à jornada de trabalho.

5 Idem 2.
}

Laborare. Ano I, Número 1, Julho/2018, pp. 31-61. ISSN 0000-0000. http://trabalhodigno.org/laborare 


\section{Quadro I - Cálculo de condições necessárias para a prática de microlesões trabalhistas}

- A perspectiva de lucro com a prática da lesão está relacionada com a inequação:

$$
\mathrm{V}>\mathrm{P}
$$

em que $\mathrm{V}$ é o valor auferido com a lesão e $\mathrm{P}$ o valor despendido com perdas decorrentes de sanções sofridas.

- $\mathrm{O}$ valor de $\mathrm{V}$ pode ser obtido por meio da equação:

$$
\mathrm{V}=\mathrm{I} \times \mathrm{N}
$$

em que I corresponde ao valor médio da lesão individual e $\mathrm{N}$, ao número de vítimas da lesão.

- $\mathrm{O}$ valor de $\mathrm{P}$ pode ser obtido por meio da equação:

$$
\mathrm{P}=\mathrm{N} \times \mathrm{D} \times \mathrm{R} \times \mathrm{A} \times \mathrm{W}
$$

em que $\mathrm{N}$ corresponde ao número de vítimas; D à probabilidade de detecção da lesão; $\mathrm{R}$ à probabilidade de reclamação das pessoas que detectaram a lesão; $\mathrm{A}$ à probabilidade de aplicação de sanções; e W ao valor esperado das sanções decorrentes de somatório de multas e dever reparatório. 
$\rightarrow$ Desse modo, para que haja perspectiva de lucro com a prática da lesão a direitos trabalhistas, temos:

$$
\text { I x } \mathrm{N}>\mathrm{N} \times \mathrm{D} \times \mathrm{R} \times \mathrm{A} \times \mathrm{W} \text {. }
$$

Portanto,

$$
\mathrm{I}>\mathrm{D} \times \mathrm{R} \times \mathrm{A} \times \mathrm{W}
$$

Fonte: Elaboração própria 6 .

Quanto maior for a probabilidade de aplicação de sanções e quanto mais severas forem estas, em especial se trouxerem perdas adicionais à mera restituição do valor ilegalmente sonegado, menos atrativa ao empresário se torna a prática da lesão.

No ramo do Direito do Consumidor, um dos mais claros e viscerais exemplos de como funcionam na prática os cálculos de custo x benefício em lesar pessoas é o caso "Ford Pinto", um dos maiores - senão o maior - escândalo da indústria automobilística mundial. O Recurso Inominado no 71001249796 (Rio Grande do Sul, 2007) assim narrou o caso:

Um caso real, paradigmático, bem ilustra a necessidade da função punitiva da responsabilidade civil em certas circunstâncias. Trata-se do célebre caso norte-americano "Grimshaw v. Ford Motor Co.", julgado em 1981 pela Suprema Corte da Califórnia (vol. 174 do California Reporter, p. 348 - Ct. App. 1981). Dez anos antes, a companhia Ford estava projetando um novo modelo de carro - o Ford modelo Pinto. Constatou-se que a colocação do tanque de combustível num determinado espaço da parte posterior do veículo

\footnotetext{
6 Observação: o presente quadro é meramente exemplificativo e não considera fatores como valores variáveis de lesão a cada vítima e possibilidade de aplicação de sanções por diferentes órgãos, dentre múltiplas outras variáveis que podem influenciar valores e cálculos probabilísticos.
}

Laborare. Ano I, Número 1, Julho/2018, pp. 31-61. ISSN 0000-0000. http://trabalhodigno.org/laborare 
resultaria na economia de quinze dólares por unidade fabricada. Todavia, as simulações mostraram que havia risco de explosão do veículo, acaso estivesse com o tanque cheio, com a seta de direção acionada e viesse a sofrer um abalroamento por trás, em determinada angulação, sofrendo um impacto acima de determinada velocidade.

Foram feitos cálculos de probabilidade para saber quantos acidentes com tais características poderiam acontecer, e analisou-se a possibilidade de algumas famílias das vítimas se darem conta de que se tratava de um risco calculado e assumido pela Ford. Diante da dificuldade de provar todos os fatos constitutivos do direito das vítimas, calculou-se que havia um risco de perder apenas três ou quatro demandas. Os advogados da empresa então informaram que, na época, os tribunais norte-americanos costumavam fixar valores em torno de trezentos mil dólares por vítima fatal de acidente de trânsito. Foram então feitos os cálculos sobre quanto a empresa economizaria com a localização do tanque de gasolina naquela posição e quanto a empresa provavelmente teria que pagar em demandas judiciais futuras. Como o resultado foi positivo, o projeto foi aprovado e executado.

Como previsto, os acidentes ocorreram. Na maioria deles, os envolvidos não se deram conta que se tratava de erro de projeto. No caso da família Grimshaw, porém, houve tal percepção. Na ação judicial movida contra a montadora, por uma série de circunstâncias casuais, a família Grimshaw conseguiu demonstrar como a Ford havia conduzido seus cálculos de custos/benefícios. Em primeiro grau de jurisdição, o júri (que, como é sabido, nos Estados Unidos atua também nas ações civis de reparação de danos) fixou uma indenização de cento e vinte e cinco milhões de dólares. Em grau de recurso, a Ford conseguiu reduzir a indenização para três milhões e quinhentos mil dólares. Uma redução substancial, sem dúvida, mas mesmo assim ficou-se num patamar que representava um valor dez vezes superior àquele que se costumava conceder a outras vítimas de acidente.

Qual a razão de não se dar à família Grimshaw os mesmos trezentos mil dólares que se costuma conceder por vítimas fatais, e sim um valor mais de dez vezes superior àquele? A razão foi a função punitiva da responsabilidade civil (punitive damages, como são conhecidos naquele país). Isso porque se à família Grimshaw tivesse sido concedido apenas os normais trezentos mil dólares (seria a normal função compensatória da responsabilidade civil em caso de morte), a diretoria da Ford, assim que anunciado o veredicto, deveria sair para comemorar o brilhantismo de sua 
estratégia econômica, pois já haviam eles previsto tal custo e já tinham garantido o lucro.... Com isso não pode compactuar o Direito. Um Direito que se preste, que mereça o respeito do cidadão, deve sempre ser mais esperto do que o torto.... E, por vezes, a forma de se esvaziar o lucro indevido do "torto" é mediante a aplicação da função punitiva.

De modo geral, as práticas de inadimplemento total de direitos e de lesões individuais ostensivas não costumam ser atrativas, pois quanto maior e mais grosseiro for o referido inadimplemento, e quanto maiores forem os recursos técnicos do lesionado para buscar medidas reparatórias e punitivas ao empresário devedor, menores as perspectivas de este sair impune e com lucro.

No Direito Laboral, a expressão máxima disso é a submissão a trabalho escravo, que torna o infrator passível de pena de prisão e de pesadas sanções financeiras, inclusive sujeito a restrições a créditos bancários. Não se trata, assim, de penalidade que, se aplicada for, seja tolerável pelo infrator penalizado. Como tentativa de impedir ou minimizar as sanções, frequentes são os casos de labor escravo envolvendo cerceamento da liberdade das vítimas, escolha de pessoas desprovidas de condições de reclamar (como imigrantes ilegais ou trabalhadores em estado máximo de hipossuficiência), trabalho em locais geograficamente isolados sem a presença de autoridades públicas e uso de "gatos" e "laranjas" para ocultar a autoria das infrações.

Assim, em sistemas jurídicos em que alguma resposta estatal seja possível e esperada, a técnica de auferição de lucro mediante lesões a credores invariavelmente é direcionada às práticas passíveis de penalidades mais brandas e de baixas taxas de detecção e reclamação pela vítima, bem como de tratamento leniente pelas autoridades públicas. A microlesão se encaixa com perfeição em tal perfil. 
Sendo a lesão diminuta ou sutil, a probabilidade de o credor vir a detectá-la é reduzida e, mesmo que a lesão seja descoberta, em razão de seu pequeno montante, a tomada de medidas de reclamação e cobrança se torna, muitas vezes, mais onerosa do que suportar o prejuízo. Ainda que a reclamação seja levada adiante, a probabilidade de o infrator vir a sofrer tratamento brando de autoridades judiciais e administrativas em face ao pequeno valor da lesão individual é bastante elevada.

Vale lembrar que a ocorrência de reclamações e de punições no caso de uma microlesão é esperada pelo infrator e faz parte de tal esquema de auferição ilícita de lucro em detrimento de terceiros. Com a multiplicação de vítimas, estatisticamente, é previsto que parte delas venha a detectar a lesão e que uma fração deste último grupo venha a efetivamente reclamar. Ainda que as sanções geradas nesses casos individualmente possam parecer desfavoráveis ao devedor, se consideradas dentro do contexto do total de casos em que a microlesão fora praticada, o saldo invariavelmente resta amplamente positivo ao devedor e infrator.

\section{ROTATIVIDADE E ASSÉDIO MORAL COMO ESTRATÉGIAS DE REDUÇÃO DE PROBABILIDADE DE DETECÇÃO, RECLAMAÇÃO E SANÇÃO}

As condições para o êxito da implementação da gestão do trabalho por microdanos aos empregados são inexoráveis e delas dependem a decisão do empregador. No entanto, a incidência desses requisitos é passível de manipulação e comumente forjada para aumentar a probabilidade de sua satisfação. A rotatividade de empregados e o assédio moral são dois dos instrumentos utilizados por empregadores para mascarar as microlesões e obstar sua detecção, reclamação e sanção.

A rotatividade de empregados consiste em formalizar contratos de trabalho por curtos períodos, sendo uma ferramenta eficaz na redução das chances de reclamação do 
direito inadimplido. Isso porque quanto menor for o período que um trabalhador permanecer trabalhando na empresa, mais agressiva poderá ser a microlesão e maior será o dano mensal que o trabalhador irá suportar antes de atingir seu limiar. Por exemplo, se em determinado emprego um trabalhador sofre prejuízo mensal de cem reais decorrente de verba salarial não adimplida, ao final do período de 5 anos haverá crédito acumulado e não corrigido monetariamente de pelo menos 6 mil reais. A chance de um trabalhador lesado vir a cobrar tal prejuízo é razoável. Caso a mesma lesão se repita ao longo dos mesmos 5 anos, mas seja praticada contra 10 trabalhadores que se sucederam na mesma função, cada um acumulando 6 meses de contrato antes de ser substituído pelo próximo, a lesão individual a cada um será de 600 reais. A probabilidade de que todos venham a demandar em juízo e cobrar os mesmos 6 mil reais sonegados é consideravelmente inferior. Assim, quanto maior for a rotatividade, menor a chance da microlesão ser objeto de cobrança pela vítima.

Ainda, a alta rotatividade está intimamente relacionada a microlesões praticadas em matéria de segurança e medicina laboral, isto é, submissão do trabalhador a pequenas agressões diárias à sua saúde. Exemplos típicos são a sujeição a condições de má ergonomia ou a algum agente químico carcinogênico, cuja doença decorrente se manifesta meses, senão anos após sua exposição. Nesse sentido, a alta rotatividade é instrumento que permite a perpetuação de condições precárias de trabalho que, se mantidas fossem em contratos de longa duração, acarretariam em inevitável pandemia de doenças nos quadros de trabalhadores ativos da empresa. Isso não significa dizer que a manutenção de contratos curtos evita o adoecimento; tão somente cria lapso temporal entre o término do vínculo empregatício e a manifestação dos sintomas da doença, dificultando o estabelecimento de nexo causal entre ela e o trabalho e, consequentemente, a responsabilização da empresa. 
O Quadro II ilustra a alteração das condições necessárias para a prática das microlesões trabalhistas quando há o uso do estratagema da rotatividade de empregados:

\section{Quadro II - Alteração das condições para a prática de microlesões trabalhistas quando implementado o artifício da rotatividade de empregados}

- O valor "gatilho" da reclamação ou valor limiar da lesão (G) é calculado da seguinte forma:

$$
\mathrm{G}=\mathrm{I} \times \mathrm{Q}
$$

em que I é o valor individual de cada lesão à vítima e Q a quantidade de repetições de lesões à vítima.

- Ocorrendo as repetições de forma repetitiva e periódica no tempo em que a vítima permanece na empresa $(\mathrm{T})$, chega-se que a quantidade de repetições (Q) é proporcional ao tempo:

$$
\mathrm{T} \sim \mathrm{Q}
$$

$\rightarrow$ Quanto menor for o tempo, maior poderá ser a lesão individual até o liminar da lesão ser alcançado. Logo:

$$
\mathrm{G}=\mathrm{I} \times \mathrm{T}
$$

Fonte: Elaboração própria 
$\mathrm{O}$ assédio moral é o segundo instrumento utilizado por empregadores para mascarar as microlesões e obstar sua detecção, reclamação e sanção. Trata-se, pois, do assédio moral organizacional, o qual consiste em forma de gestão da mão de obra, como conceituam Gosdal e Sobol:

O assédio organizacional é um conjunto sistemático de práticas reiteradas, inseridas nas estratégias e métodos de gestão, por meio de pressões, humilhações e constrangimentos, para que sejam alcançados determinados objetivos empresariais ou institucionais, relativos ao controle do trabalhador (aqui incluído o corpo, o comportamento e o tempo de trabalho), ou ao custo do trabalho, ou ao aumento de produtividade e resultados, ou exclusão ou prejuízo de indivíduos ou grupos com fundamentos discriminatórios (Gosdal, Soboll, 2009, p. 37).

Nos casos onde há lesões sistemáticas de direitos trabalhistas, quanto menos tempo o trabalhador se mantiver no emprego, menores serão o débito individual e a chance de esse vir a ser reclamado pelo credor. Contudo, demitir trabalhadores de forma imotivada e arbitrária, a fim de promover rotatividade, sujeita empregadores a custos adicionais decorrentes da prática de demissão imotivada - como a multa de $40 \%$ sobre os depósitos do fundo de garantia ${ }^{7}$ - o que é indesejável sob o aspecto financeiro. Logo, ao praticante da microlesão, interessa que os trabalhadores voluntariamente se desliguem da empresa, isto é, peçam demissão.

A submissão a condições de trabalho precárias e a sonegação de direitos trabalhistas são fatores naturalmente convidativos para que o trabalhador venha a pedir desligamento na busca de um emprego melhor. No entanto, se essas práticas não forem suficientes para promover a alta rotatividade almejada, o assédio moral, muitas vezes, se mostra um instrumento eficaz para tanto.

7 Prevista pelo parágrafo 10 do artigo 18 da Lei 8036/90.

Laborare. Ano I, Número 1, Julho/2018, pp. 31-61. ISSN 0000-0000. http://trabalhodigno.org/laborare 
Sob a lógica empresarial, o dispêndio de recursos humanos e financeiros em rotinas de humilhação, isolamento e depreciação pode parecer irracional e contraproducente. Não há ganho aparente em criar essas situações e em tolerar que supervisores e empregados deliberadamente gastem tempo, energia e recursos financeiros com ações indutoras de doenças psíquicas, absenteísmo e desagregação de equipes de trabalho. Salvo se o propósito for justamente provocar o desligamento voluntário daqueles alvos da ação de assédio.

Dentro da rotina da prática de microlesões, o assédio moral se encaixa com perfeição. Um dos casos mais notórios é o da empresa francesa France Telecom e o programa de demissões ocorrido a partir de 2004 em seu país sede. A fim de acelerar o atingimento da meta de corte de empregados, tal empresa passou a deliberadamente assediar moralmente funcionários para forçar pedidos de demissão, provocando 60 suicídios entre 2006 e 2009. Em 2016, os dirigentes responsáveis foram acusados criminalmente pela promotoria de justiça parisiense (RFI, 2016).

\section{MICROLESÃO E DUMPING SOCIAL}

A sonegação sistemática de direitos trabalhistas é conhecida como dumping social. Também chamada de dano social, a referida prática consiste na ação deliberada das empresas de desrespeitar direitos trabalhistas, a fim de obterem lucro e vantagem econômica sobre seus concorrentes. Os efeitos do dumping social são a precarização do trabalho, a concorrência desleal e a violação à ordem jurídica, social e econômica estabelecidas - com afronta à dignidade da pessoa humana e aos direitos fundamentais mais básicos à saúde e à segurança no trabalho.

Nesse sentido, o Enunciado n ${ }^{\circ} 4$ da Associação Nacional dos Magistrados da Justiça do Trabalho - ANAMATRA (2007) informa que: 
4. "DUMPING SOCIAL". DANO À SOCIEDADE. INDENIZAÇÃO SUPLEMENTAR. As agressões reincidentes e inescusáveis aos direitos trabalhistas geram um dano à sociedade, pois com tal prática desconsidera-se, propositalmente, a estrutura do Estado social e do próprio modelo capitalista com a obtenção de vantagem indevida perante a concorrência. A prática, portanto, reflete o conhecido "dumping social", motivando a necessária reação do Judiciário trabalhista para corrigi-la. $\mathrm{O}$ dano à sociedade configura ato ilícito, por exercício abusivo do direito, já que extrapola limites econômicos e sociais, nos exatos termos dos arts. 186, 187 e 927 do Código Civil. Encontra-se no art. 404, parágrafo único do Código Civil, o fundamento de ordem positiva para impingir ao agressor contumaz uma indenização suplementar, como, aliás, já previam os artigos 652, "d", e 832, § 1º da CLT.

As microlesões trabalhistas são uma das principais formas de dumping social e podem se manifestar das mais variadas maneiras, sendo limitadas tão somente pela criatividade do infrator e por seu grau de esforço em ocultar a lesão. De modo geral, elas consistem em furtos isolados e discretos de direitos trabalhistas, eis que, quanto menor e mais intrincada for a lesão, menor sua chance de detecção.

Aspectos pessoais da vítima como nível de escolaridade, experiência profissional, acesso à orientação jurídica e eficácia da atuação do respectivo sindicato laboral são fatores que aumentam a possibilidade de detecção da lesão. O grau de hipossuficiência do trabalhador pode tanto aumentar quanto reduzir a taxa de detecção: por um lado, um trabalhador com maior salário e nível educacional pode ser mais propenso a encontrar fraudes de maior complexidade, mas, ao mesmo tempo, pode tender a desconsiderar a lesão e se manter passivo em face de pequenos déficits "irrelevantes" cuja falta não seria considerada como tal a um trabalhador que recebe salário mínimo.

Essas práticas são maliciosas porque prevêem o adimplemento parcial de direitos aos trabalhadores de modo que as empresas infratoras conseguem manter a aparência de legalidade em suas condutas, minimizando as consequências caso venham a ser Laborare. Ano I, Número 1, Julho/2018, pp. 31-61. ISSN 0000-0000. http://trabalhodigno.org/laborare 
flagradas praticando os ilícitos. Nesse contexto, tanto empregadores como órgãos de regulação do trabalho tendem a tratar aquela infração como um "erro", desvio ou caso isolado, mesmo quando acomete milhares de trabalhadores da mesma empresa.

Um elemento normalmente diferenciador entre uma microlesão decorrente de um equívoco honesto e verdadeiro e uma microlesão proposital praticada no contexto de dumping social é a recalcitrância, isto é, a continuidade da repetição da mesma infração após respectiva detecção e condenação administrativa ou judicial. Tratandose de real equívoco, a tendência natural é o empresário fazer cessar a lesão, uma vez que não é natural a insistência em práticas irregulares e submissão inútil da empresa a prejuízos decorrentes de gastos com advogados, multas administrativas e/ou condenações judiciais por mera resistência em admitir que errou culposamente.

Por outro lado, se a lesão continua a ser praticada mesmo após a penalização da empresa, é inevitável a conclusão de que a mesma não só está auferindo lucro com a prática, mas também de que se trata de estratégia empresarial que garante competitividade no mercado de trabalho mesmo com a imposição de sanções estatais.

Exemplo do dano social causado em decorrência da prática de microlesões é o caso da empresa Contax Mobitel. Após recorrentes fiscalizações do Ministério do Trabalho e do Ministério Público do Trabalho, em que foram lavrados Autos de Infração consignando as irregularidades constatadas, a empresa foi flagrada exigindo o cumprimento de metas excessivas e proibindo os trabalhadores de exercerem necessidades fisiológicas básicas, como beber água e ir ao banheiro. A consequência das infrações foi o desenvolvimento de patologias osteomusculares, de perdas auditivas, de infecções urinárias e de outras doenças que levavam os trabalhadores a apresentarem mais de 6 (seis) mil atestados médicos por mês ao empregador, que empregava cerca de 14 (quatorze) mil pessoas (Clemente, 2015). 
A estratégia de organização do trabalho adotada pela Contax prejudicou a saúde de milhares de trabalhadores, extrapolando o âmbito do locus ocupacional e impactando o sistema de saúde e a previdência social. De acordo com o juiz que condenou a empresa de teleatendimento a pagar uma indenização em sede de Ação Civil Pública movida pelo Ministério Público do Trabalho (MPT, 2016):

Os abusos e ilegalidades praticados pela ré, por anos, certamente trouxeram prejuízos a uma coletividade indeterminada de trabalhadores e, também, aos respectivos familiares. Basta imaginar que várias pessoas devem ter trabalhado doentes, visando exatamente não apresentar atestados ou mesmo suportar os riscos de redução do padrão remuneratório.

As ações da empresa promoviam, ainda, a discriminação entre as profissões de médico e de outros profissionais da saúde como fisioterapeutas e de dentistas, por exemplo, ao adotar como prática a recusa do recebimento de atestados médicos emitidos por esses profissionais. Assim, o dano causado pelas práticas microlesivas da empresa atingiu, além dos trabalhadores diretamente vinculados a ela, os trabalhadores de diversas áreas da saúde. Os prejuízos decorrentes de ações discriminatórias são extensos e difusos e, portanto, de difícil mensuração. Sua condenação por meio da precificação é o instrumento de que o Direito dispõe para controlar sua ocorrência na sociedade, adotando-se como pressuposto a impossibilidade de superação do conflito nas formações econômicas capitalistas, mas tão somente de sua regulação pelo Estado (Marx, 2013).

\section{O ESTADO COMO CHANCELADOR DA PRÁtiCA DE MICROLESÕES TRABALHISTAS}

No âmbito do Direito do Consumidor, é reconhecida a desigualdade entre fornecedor e consumidor, devendo o primeiro indenizar sempre que causar dano, 
independentemente de culpa. A regra geral da teoria objetiva contida no Código de Defesa do Consumidor tem o condão de desestimular os danos ou lesões (SILVESTRE, 2017).

$\mathrm{Na}$ esfera trabalhista, a assimetria de forças entre empregado e empregador é positivada por meio dos Princípios da Proteção, da Irrenunciabilidade, da Primazia da Realidade e da Continuidade da Relação de Emprego. O Princípio Protetor, na classificação de Rodriguez (2000, p. 44-67), engloba as seguintes regras: a) in dubio pro operário; b) norma mais favorável; c) condição mais benéfica.

Esses princípios norteiam o Direito do Trabalho brasileiro e traduzem valores que visam compensar a hipossuficiência do trabalhador nas relações de trabalho. Por isso, servem de balizamento para ações e interpretações judiciais e administrativas dos agentes públicos que operam no mundo do trabalho.

No entanto, o que se verifica no Ministério do Trabalho é que as ações e interpretações predominantemente adotadas pelos agentes do Sistema Federal de Inspeção do Trabalho - tanto por aqueles responsáveis por determinar as diretrizes gerais institucionais, como por aqueles que aplicam essas diretrizes em campo muitas vezes e pelos mais diversos motivos, desconsideram os princípios supramencionados.

Em 2015, por exemplo, a Secretaria de Inspeção do Trabalho estabeleceu que infrações praticadas de forma repetitiva e sucessiva devem ser consideradas como se uma só fossem, caso flagradas na mesma ação fiscal (BRASIL, 2014 e 2015).

Em 20/11/2017, a Coordenação Geral de Recursos reforçou o entendimento e informou aos Auditores-Fiscais do Trabalho analistas que eventuais processos com decisão em 
contrário, ou seja, que considerassem cada infração como uma infração, seriam devolvidos para reforma da decisão ${ }^{8}$. Isto é, se um empregador sonega sistematicamente o depósito do FGTS, deixando de pagar parcelas mensais sucessivas - cada uma delas com base de cálculo e data de vencimento diversas - a orientação do órgão trabalhista é que o empregador seja multado como se tivesse deixado de pagar apenas uma única parcela. Isso consiste numa confusão conceitual entre infração permanente, como, por exemplo, manter um trabalhador sem carteira assinada, e infrações continuadas, como o exemplo da sucessiva sonegação de parcelas mensais do FGTS. Tal entendimento não tem outro resultado senão beneficiar praticantes de dumping social, uma vez que equipara o infrator que deixou de recolher propositalmente sessenta parcelas mensais de FGTS em período de cinco anos ao infrator que, no mesmo período e por lapso de distração, deixou de recolher apenas uma.

Outro exemplo é a expedição da Instrução Normativa 133/2017, relativa à aplicação da Norma Regulamentadora 12 (NR 12) que regulamenta segurança de máquinas. Apesar de a NR 12 ter sido introduzida em 1979, de trazer exigências que já constavam no texto original da CLT de 1943 e de ter sido reeditada múltiplas vezes e em cada alteração ser renovada sua vacatio legis, a Instrução Normativa 133/2017 (BRASIL, 2017a) estabeleceu que empresas somente podem ser penalizadas após serem flagradas praticando irregularidades e caso essas persistam após prazo proposto pela própria empresa. Isto é, fulmina a eficácia erga omnes da norma e estabelece que a NR 12 somente passa a valer após o próprio infrator escolher e estabelecer um lapso

\footnotetext{
8 O Memorando no 074/2014/SEINT/SRTE-TO e o informe da Coordenação Geral de Recursos, feito por e-mail aos Auditores-Fiscais do Trabalho analistas, contrariam a Consolidação das Leis do Trabalho (artigo 628: "Salvo o disposto nos arts. 627 e 627-A, a toda verificação em que o Auditor-Fiscal do Trabalho concluir pela existência de violação de preceito legal deve corresponder, sob pena de responsabilidade administrativa, a lauratura de auto de infração") , além do artigos 18, inciso XVIII, e 24 do Decreto 4.552/02: art. 18 - "Compete aos Auditores-Fiscais do Trabalho, em todo o território nacional: (...) XVIII - laurar autos de infração por inobservância de disposições legais; art. 24 - "A toda verificação em que o Auditor-Fiscal do Trabalho concluir pela existência de violação de preceito legal deve corresponder, sob pena de responsabilidade, a lauratura de auto de infração (....)"
}

Laborare. Ano I, Número 1, Julho/2018, pp. 31-61. ISSN 0000-0000. http://trabalhodigno.org/laborare 
temporal próprio para passar a se sujeitar à norma. De norma geral e impositiva, a NR 12 passou a se tratar de norma cuja eficácia depende da anuência do administrado em se submeter a ela.

Essas atuações flexibilizam a aplicação da legislação e abrandam a penalização do infrator, que não é estimulado a cumprir a lei em momento prévio à fiscalização. Dessas opções dos agentes estatais decorrem maiores índices de fraudes, acidentes do trabalho, adoecimentos, mortes e, consequentemente, a manutenção da desigualdade social.

Por outro lado, a política do governo de sucateamento do Ministério do Trabalho, bem como de ausência de revisão dos valores das multas aplicadas por esse órgão são fatores de aumento da precarização das relações de trabalho porque o Estado não consegue se fazer presente para coibir as práticas fraudulentas. $\mathrm{O}$ estrangulamento do Sistema Federal de Inspeção do Trabalho tem se dado por meio de restrições orçamentárias e pela ausência de realização de concursos públicos para a reposição do quadro de inspetores. Em junho de 2017, havia 2.409 auditores-fiscais do trabalho para inspecionar todo o Brasil; ao todo, havia 1.235 cargos criados em lei, mas não ocupados por falta de realização de concurso público. Em 2014, a proporção era de 1 inspetor para cada 23.571 trabalhadores, segundo a RAIS/2014 e o SFIT ${ }^{9}$ 12/2014. A impunidade das empresas transgressoras é garantida, desse modo, também por meio da própria extinção do órgão fiscalizador e da compensação pecuniária da infração ${ }^{10}$.

O Ministério Público do Trabalho segue linha similar à do Ministério do Trabalho. Verifica-se ampla predileção dos Procuradores do Trabalho pela propositura de TACs

9 Sistema Federal de Inspeção do Trabalho.

10 Por exemplo, o valor da multa trabalhista mais baixa é $R \$ 2,13$. Para o Direito Ambiental, esse valor é $R \$$ 50,00 e para o Direito Previdenciário, $R \$ 173,00$. Já os maiores valores de multa são, respectivamente, $R \$$ 42.564,00, R\$ 50.000.000,00 e R\$ 214.301,53. Fonte: Apresentação 'A Inspeção do Trabalho no Brasil: Trajetória, desafios e perspectivas', realizada por Magno Riga no Fórum da Inspeção do Trabalho na Unicamp, em 2016.

Laborare. Ano I, Número 1, Julho/2018, pp. 31-61. ISSN 0000-0000. http://trabalhodigno.org/laborare 
- Termos de Ajustamento de Condutas sem previsão de indenização pelo dano social causado, em detrimento do ajuizamento de ações civis públicas que prevejam um montante condenatório superior ao lucro auferido com as práticas ilícitas. Esses acordos são realizados mesmo em casos de flagrantes de trabalho escravo e de infrações reiteradamente praticadas pelos mesmos infratores.

Conforme relata Souza (2016, p. 93), nos anos de 2013, 2014 e 2015, foram firmados, respectivamente, $12.172,11.746$ e 9.947 TACs e apenas $2.625,2.790$ e 2.566 Ações Civis Públicas em todo o Brasil. No Estado de São Paulo, a análise de 547 TACs revelou que apenas $3 \%$ previam a imposição de indenização social aos infratores (SOUZA. 2016, p. 114).

A despeito dos TACs produzirem documento com efeito de sentença transitada em julgado, tais termos invariavelmente dependem da vontade e aceitação do próprio devedor, de modo que o poder de barganha do Ministério Público do Trabalho tem como limite o lucro do infrator. A este somente é vantajosa a assinatura de acordos que consistam em vitórias pírricas ao Parquet. Qualquer outro resultado é indesejável, isto é, onde o balanço entre lucros decorrentes da irregularidade e perdas decorrentes da sanção penda em favor do último e não do primeiro. Nesses casos, a aposta na inércia do Ministério Público em demandar judicialmente ou no comportamento errático da Justiça se torna o caminho mais lógico.

$\mathrm{Na}$ esfera judicial, direitos são renunciados por meio de acordos e concessões promovidas, inclusive, pelo Conselho Nacional de Justiça (sob o lema 'Conciliar é Legal'. O Conselho Superior da Justiça do Trabalho aprovou, em setembro de 2016, resolução (BRASIL, 2016a) que normatiza os procedimentos de mediação e prevê a criação de Centros de Conciliação, o que indica o caráter predominantemente conciliatório do órgão, em detrimento de uma política de enfrentamento da 
ilegalidade). Entre os anos de 2005 a 2015, a média de conciliações no país foi de 42,5\% (BRASIL, 2017b) e, em 2015, foram pagos a reclamantes mais de 17 bilhões de reais, dos quais mais de 8 bilhões ou $48,15 \%$ foram quitados em acordos ou pagos "de forma espontânea" pelos empregadores ${ }^{11}$ (BRASIL, 2017c).

Os assuntos mais recorrentes na primeira instância nesse ano - Aviso Prévio (892.488 processos), Multa Rescisória (710.989 processos) e Multa de 40\% do FGTS (616.245 processos) (RIO GRANDE DO SUL, 2007) - tratam de verbas atinentes ao término da relação de emprego. Ainda, apenas 6,4\% das ações em fase de conhecimento foram consideradas improcedentes (BRASIL, 2016b), o que significa que, em quase 95\% dos casos, reconheceu-se que os direitos pleiteados haviam sido frustrados pelas reclamadas nos cursos dos contratos de trabalho.

Esses números indicam que a grande maioria das reclamatórias propostas na Justiça do Trabalho decorre de valores devidos e não pagos pelos empregadores, que esperam ser acionados judicialmente para adimplirem suas obrigações legais. Não obstante, a política institucional predominante desse órgão é a promoção da conciliação, ou seja, o estímulo que as partes acordem com determinado valor: naturalmente, o empregador apenas aceitará pagar fração do que é realmente devido. Afinal de contas, se estivesse disposto a pagar valor justo não haveria sequer o inadimplemento inicial e consequente razão para haver cobrança judicial. Sob aspecto econômico, sendo o pior cenário esperado uma condenação do valor justo, não é lógico pagar a totalidade da dívida enquanto houver chance de, por erro judicial, haver exoneração total ou parcial desta. O empregado tenderá a aceitar o que for proposto pelo juízo, seja por se tratar de verba alimentar à qual não pode aguardar anos ou décadas para receber, seja pelo risco de erro judicial. Em suma, um acordo

" Mais especificamente, $R \$ 17.444 .524 .839,77$ e $R \$ 8.399 .803 .923,45$.

Laborare. Ano I, Número 1, Julho/2018, pp. 31-61. ISSN 0000-0000. http://trabalhodigno.org/laborare 
judicial, na maioria das vezes, trata de um calote parcial ao trabalhador feito com a concordância do Estado.

Em todas as esferas trabalhistas não há, via de regra, imposição do pagamento de indenização pelos danos causados ao trabalhador, que precisa reclamar legalmente para ter seu direito adimplido, às empresas concorrentes cumpridoras das obrigações, que sofreram concorrência desleal, e ao próprio poder público, que arca com o custo da existência e da manutenção do aparato administrativo e judicial de imposição da lei trabalhista. A indenização tem a função de ensinar e incentivar as empresas a cumprirem a legislação, interferindo pedagogicamente no cálculo custo $\mathrm{x}$ benefício para a prática dos microdanos. Da mesma forma, a ausência de utilização desse instrumento é igualmente uma forma de ensinar ao infrator que o descumprimento da legislação é compensatório.

Observa-se, pois, que, no Brasil, a lógica institucional utilizada para combate aos efeitos da microlesão na esfera trabalhista retroalimenta a situação. Ao invés de os processos judiciais e administrativos trabalhistas primarem pela promoção de ações coletivas e penalização exemplar de empresas que repetidamente são condenadas pelos mesmos motivos, prega-se a prática da "conciliação" entre as partes, submetendo, assim, à vontade do próprio devedor como e quanto este deseja pagar para a vítima da lesão e/ou ser punido. A escolha do devedor, por óbvio, não será outra senão qualquer valor que torne a continuidade da prática do dumping social lucrativa, reincidindo num ciclo interminável de lesões feitas com chancela estatal. Quanto mais uma empresa sonega direitos e mais acordos faz com quitação parcial, mais é incentivada a continuar sonegando. E quanto mais sobrecarregados estiverem os órgãos públicos, menos confiável e eficaz será sua resposta, tornando ainda mais convidativo o inadimplemento de obrigações.

Laborare. Ano I, Número 1, Julho/2018, pp. 31-61. ISSN 0000-0000. http://trabalhodigno.org/laborare 


\section{CONCLUSÃO}

O Direito do Trabalho, expresso pela legislação trabalhista vigente em determinada sociedade, tem a finalidade de regulamentar as relações entre empregador e empregado, estabelecendo limites à exploração do trabalho. Ao traçar esses limites, o Direito legitima a parcela de exploração que é socialmente pactuada como admissível.

Não obstante a referida aceitação social de quantitativos exploratórios, há ainda constante tensão por parte do segmento patronal para o aumento desses níveis. O tensionamento ocorre por diversas vias, como a do legislativo, pela qual se aprovam leis que lhes são mais favoráveis ${ }^{12}$, e como a da práxis, com a negação e burla dos direitos trabalhistas.

Analisamos nesse artigo a segunda forma de tensionamento, qual seja, a práxis das empresas de frustrarem direitos trabalhistas, procurando demonstrar que as fraudes trabalhistas, quando operadas de forma sistemática, não ocorrem de forma aleatória. Pelo contrário, consistem em forma de gestão do trabalho que permite ao empregador maior obtenção de lucros a partir de diferentes formas de exploração do trabalho. Isso significa dizer que as empresas as praticam intencionalmente e com o objetivo de se manterem vivas frente à concorrência.

Foi com a finalidade de tornar mais fácil a visualização desse fenômeno que transpusemos o conceito de microlesão do Direito do Consumidor para o Direito Trabalhista, expondo que a lesão causada por empregadores a trabalhadores, inclusive causando a morte desses, é deliberada e se justifica pela necessidade de obtenção de lucro e ganho de competitividade no mercado de trabalho capitalista. Tal como ocorre com

12 Como se observou recentemente com a aprovação da Lei da Terceirização e da chamada Reforma Trabalhista.

Laborare. Ano I, Número 1, Julho/2018, pp. 31-61. ISSN 0000-0000. http://trabalhodigno.org/laborare 
relação ao consumidor, os microdanos aos empregados caracterizam-se pela repetição de ações prejudiciais que, do ponto de vista individual, possuem aparente irrelevância, mas que são consideravelmente vantajosas quando consideradas na totalidade.

Por fim, procuramos demonstrar que a omissão do Estado em tutelar direitos básicos dos trabalhadores e em aplicar sanções que impliquem em prejuízos reais às empresas, naturalmente as induz a práticas de concorrência desleal mediante dumping social e privilegia não o empregador mais produtivo e eficaz, mas aquele mais hábil em descumprir a lei sem sofrer consequências.

A política de governo aplicada ao Ministério do Trabalho, ao Ministério Público do Trabalho e à Justiça do Trabalho aliada a práxis dos agentes públicos dos órgãos de regulação do trabalho de flexibilizarem a aplicação da legislação vigente, contribui para a impunidade dos infratores e, consequentemente, para a reprodução dos comportamentos empresariais fraudulentos. Em última análise, todas essas medidas, tanto internas como externas às instituições públicas, conformam políticas públicas trabalhistas de pacto com o capital em detrimento do ser humano trabalhador.

\section{Agradecimentos - Os autores agradecem à Fernanda Sampaio pela revisão geral, Magno Riga e Rafael Castro pela crítica, e Ricardo Batista pela revisão do Quadro I.}




\section{REFERÊNCIAS BIBLIOGRÁFICAS}

Anamatra - Associação Nacional dos Magistrados da Justiça do Trabalho. Enunciado $\mathrm{n}^{\mathrm{o}}$ 4. $1^{\mathrm{a}}$ Jornada de Direito Material e Processual na Justiça do Trabalho. TST. 23/11/2007. Disponível em: http://www.amatra4.org.br/cadernos/265-caderno15? start=3. Acesso em 13 jul. 2017.

Brasil. Constituição da República Federativa do Brasil de 1988. Disponível em <http://www.planalto.gov.br/ccivil_03/constituicao/constitui\%C3\%A7ao.htm>. Acesso em 10 jul. 2017.

Brasil. Ministério do Trabalho (2014). Memorando nº 074/2014/SEINT/SRTE-TO.

Brasil. Ministério do Trabalho (2015). Informação/CGR/SIT/No 013/2015/SIT/MTE.

Brasil. Conselho Superior da Justiça do Trabalho (2016a). Resolução CSJT n. ${ }^{\circ}$ 174, de 30/09/2016.

Brasil. Relatório Geral da Justiça do Trabalho 2015. Seção 4 (2016b). http://www.tst.jus.br/consolidacao-estatistica1. Acesso em 12 de março de 2018.

Brasil. Ministério do Trabalho (2017a) Instrução Normativa no 133 do MTb, de 21 de agosto de 2017.

Brasil. Tribunal Superior do Trabalho (2017b). Disponível em: http://www.tst.jus.br/conciliacoes1. Acesso em: 24 jan. 2017.

Brasil. Coordenadoria de Pesquisa e Estatística do TST (2017c). Disponível em: http://www.tst.jus.br/documents/10157/4a29c1b4-1aa4-4ed2-8645-af8f4c66d689.

Acesso em: 24 jan. 2017.

Clemente, A. (2015). Ministério do Trabalho e Emprego interdita a Contax. Diário de Pernambuco. Publicado em: 21/01/2015. Disponível em: http://www.diariodepernambuco.com.br/app/noticia/economia/2015/01/21/internas_e conomia,555977/ministerio-do-trabalho-e-emprego-interdita-a-contax.shtml. Acesso em: 28 jul. 2017.

Gosdal, TC.; Soboll, LA. (Org.). (2009). Assédio moral interpessoal $e$ organizacional: um enfoque interdisciplinar. São Paulo: Editora LTr.

Marx, K. (2006). Manuscritos econômicos-filosóficos. Tradução de Jesus Ranieri. São Paulo: Boitempo Editorial.

Marx, K. (2013). O Capital: crítica da economia política. Livro I: o processo de produção do capital. São Paulo: Boitempo.

Laborare. Ano I, Número 1, Julho/2018, pp. 31-61. ISSN 0000-0000. http://trabalhodigno.org/laborare 
MPT - Ministério Público do Trabalho em Campinas (2016). Contax Mobitel é condenada em R \$ 1,1 milhão por recusar atestados de saúde e violar intimidade de funcionários. Disponível em: http://www.prt15.mpt.mp.br/informe-se/noticias-dompt-campinas/444-contax-mobitel-e-condenada-em-r-1-1-milhao-por-recusaratestados-de-saude-e-violar-intimidade-de-funcionarios. Acesso em: 9 set. 2017.

Rodriguez, A.P. (2000). Princípios de Direito do Trabalho. Tradução de Wagner Giglio. São Paulo: LTr.

Souza, I.F. (2016). Efetividade dos termos de ajuste de conduta firmados pelo Ministério Público do Trabalho: uma análise empírica. (Dissertação de Mestrado) Universidade Católica de Brasília.

RFI - Rádio França Internacional (2016). Após suicídio de 60 funcionários, empresa francesa é processada por assédio moral. Disponível em: http://br.rfi.fr/franca/20160707-apos-suicidio-de-60-funcionarios-empresa-francesa-eprocessada-por-assedio-moral. Acesso em: 28 jul. 2017.

Rio Grande do Sul. Tribunal de Justiça do Rio Grande do Sul. Turmas Recusais. Terceira Turma Recursal Cível. Recurso Inominado $n^{\circ}$ 71001249796. Recorrente: Jucélia Nazário Oriques. Recorrido: Kater Administradora de Eventos Ltda. Relator: Dr. Eugênio Facchini Neto. Porto Alegre, 27 de março de 2007. Lex: Diário da Justiça do dia 16/04/2007.

Rio Grande do Sul. Tribunal de Justiça do Rio Grande do Sul. Apelação Cível: AC 70056397896 RS. Diário da Justiça do dia 19/11/2013. Relator: Eugênio Facchini Neto Julgado em 13/11/2013.

Silvestre, K. (2012). Responsabilidade do profissional liberal: Pessoa jurídica pode ser profissional liberal? Revista Jus Navigandi, Teresina. Vol. 17, n. 3187. Disponível em: https://jus.com.br/artigos/21358. Acesso em: 8 abr. 2017. 